\title{
Superimposed Nephrotic Syndrome in Diabetic Patients: 15 Cases of Mismatched Clinicopathological
}

\section{Correlation}

\author{
Kamel El-Reshaid ${ }^{* 1}$, Shaikha Al-Bader ${ }^{2}$ \\ ${ }^{1}$ Department of Medicine, Faculty of Medicine, Kuwait University \\ ${ }^{2}$ Kidney unit, Amiri hospital, Ministry of health, Kuwait
}

Corresponding author: Kamel El-Reshaid; MBBCH, Am B Med, Am B Nephrology, FRCP (Ed); kamel@hsc.edu.kw

Received 29 April 2020;

Accepted 09 June 2020;

Published 04 July 2020

\begin{abstract}
The spectrum of renal disease in patients with diabetes encompasses both diabetic kidney disease (including albuminuric and non-albuminuric phenotypes) and non-diabetic kidney disease (NDKD). Acute nephrotic syndrome (NS) with short duration of diabetes indicates NDKD. Moreover, such presentation is atypical in patients with IgA nephropathy and pre-eclampsia and hence warrants kidney biopsy to rule out treatable glomerulopathy. In this case series; we present our experience with 15 patients with atypical NS and outline their management.
\end{abstract}

Keywords: diabetes mellitus, glomerulonephritis, kidney biopsy, nephrotic syndrome, superimposed

\section{Introduction}

According to the latest 2019 data, the global burden of diabetes mellitus (DM) is increasing, with a prevalence of 463 million in adults especially in the Middle East, Sub-Saharan Africa and India

${ }^{[1]}$. This increase is principally attributable to a rapid rise in cases of type $2 \mathrm{DM}$, driven by a combination of obesity, urbanization and an ageing population ${ }^{[2]}$. As such, the public health impact of diabetes-related complications is enormous, and is no better exemplified than by the rapid increase in diabetic glomerulosclerosis (DGS) which is the leading cause of end-stage renal disease $(E S R D)$ in the world with a prevalence rate at $45 \%{ }^{[3]}$. The spectrum of renal disease in patients with DM encompasses both diabetic kidney diseases (DKD) that includes albuminuric and non-albuminuric phenotypes as well as non-diabetic ones (NDKD) [4]. The term DGS defines the most common renal disease in diabetics which is characterized by with slowly progressive (a) proteinuria up to nephrotic syndrome (NS), (b) hypertension and (c) renal failure. Establishing diagnosis of DGS is an ominous finding since ESRD can't be prevented though can be delayed by antihypertensive treatment and glycemic control ${ }^{[5]}$. Traditionally, kidney biopsy is neither required nor advised in typical cases of DGS presenting with diabetic past history $>5$ years, NS, normalsized kidneys and proliferative retinopathy with absence of clinical as well as laboratory evidence of autoimmune diseases or drug-side effects ${ }^{[6]}$. However, it is essential to identify NDKD as some forms are treatable. Hence, biopsy is indicated in patients without diabetic retinopathy, short duration of DM and rapidly progressive proteinuria with/without hematuria ${ }^{[7]}$. Compared to other considerations; NS is a difficult indication for biopsy since most patients with DGS has variable degree of oedema due to proteinuria and/or renal failure. In this report, we present our experience with a spectrum of NS due to NDKD in diabetic patients and elaborate on their different management.

\section{Patients and methods}

The study was conducted by the renal unit of Al-Amiri hospital. The unit is a referral center for patients with renal disease in 2 major hospitals in the capital of Kuwait city and is a tertiary care unit for the other hospitals in Kuwait. It has adequate diagnostic as well as therapeutic facilities to care for both in- and out-patients with all medical and renal diseases. Moreover, the hospital has adequate histopathological unit for the different disciplines for medical and surgical departments. The study was conducted by retrospective analysis of our clinical and histopathological data on our diabetic patients presenting with new-onset NS. Patients were included if they had: (a) adequate kidney biopsy with for diagnosis based on light microscopy, special stains and immunofluorescence, (b) mismatched clinicopathological correlation of NS, and (c) were treated and followed up by our team.

\section{Results}

A total of 415 kidney biopsies were done in the past 5 years. Fifteen patients fulfilled the above mentioned inclusion criteria. The demographical, clinical and histopathological data are summarized in table 1 . 
Table 1: Clinical data and biopsy results in diabetic patients with abnormal presentation of NS

\begin{tabular}{|c|c|c|c|c|c|c|c|c|c|c|c|c|c|}
\hline \multirow[t]{2}{*}{$\begin{array}{l}\text { Patient's } \\
\text { number }\end{array}$} & \multirow[t]{2}{*}{ Sex } & \multirow[t]{2}{*}{$\begin{array}{l}\text { Age } \\
\text { (years) }\end{array}$} & \multirow[t]{2}{*}{$\begin{array}{l}\text { Durati } \\
\text { on of } \\
\text { DM } \\
\text { (years) }\end{array}$} & \multirow[t]{2}{*}{$\begin{array}{l}\text { Durati } \\
\text { on of } \\
\text { NS } \\
\text { (mont } \\
\text { hs) }\end{array}$} & \multicolumn{2}{|c|}{$\begin{array}{l}\text { Serum } \\
\text { albumin }\end{array}$} & \multicolumn{2}{|c|}{ Proteinuria } & \multicolumn{2}{|c|}{ Stage of $R F$} & \multirow[t]{2}{*}{$\begin{array}{l}\text { Kidney } \\
\text { biopsy }\end{array}$} & \multirow[t]{2}{*}{$\begin{array}{l}\text { Clinicopatho } \\
\text { logical } \\
\text { diagnosis }\end{array}$} & \multirow[t]{2}{*}{$\begin{array}{l}\text { Follow up } \\
\text { (months) }\end{array}$} \\
\hline & & & & & initial & final & initial & final & Initial & final & & & \\
\hline 1 & $\mathrm{~F}$ & 43 & 8 & 1 & 19 & 34 & 9 & 0.7 & 2 & 1 & DGS & MCD & 36 \\
\hline 2 & $\mathrm{~F}$ & 57 & 10 & 1 & 10 & 38 & 10 & 0.2 & 2 & 1 & DGS & MCD & 21 \\
\hline 3 & $\mathrm{M}$ & 75 & 7 & 1 & 20 & 40 & 7 & 0.1 & 2 & 1 & DGS & MCD & 18 \\
\hline 4 & $\mathrm{M}$ & 48 & 3 & 7 & 18 & 39 & 8 & 0.8 & 2 & 1 & MG & MG & 38 \\
\hline 5 & $\mathrm{~F}$ & 60 & 4 & 8 & 20 & 40 & 6 & 0.5 & 2 & 1 & MG & MG & 41 \\
\hline 6 & $\mathrm{M}$ & 46 & 4 & 3 & 18 & 36 & 5 & 2 & 3 & 2 & FSGS & FSGS & 48 \\
\hline 7 & $\mathrm{~F}$ & 58 & 8 & 4 & 10 & 20 & 7 & 3 & 3 & 5 & $\begin{array}{l}\text { Collapsing } \\
\text { FSGS }\end{array}$ & $\begin{array}{l}\text { Collapsing } \\
\text { FSGS }\end{array}$ & 37 \\
\hline 8 & $\mathrm{~F}$ & 19 & 4 & 1 & 12 & 38 & 4 & 1 & 3 & 1 & $\begin{array}{l}\text { FSGS+Eclam } \\
\text { psia }\end{array}$ & FSGS & 32 \\
\hline 9 & $\mathrm{~F}$ & 28 & 7 & 1 & 8 & 36 & 8 & 1.4 & 3 & 1 & $\begin{array}{l}\text { FSGS+Eclam } \\
\text { psia }\end{array}$ & FSGS & 52 \\
\hline 10 & $\mathrm{~F}$ & 18 & 4 & 2 & 10 & 40 & 7 & 0.1 & 2 & 1 & Eclampsia & $\begin{array}{l}\text { Eclampsia+ } \\
\text { MCD }\end{array}$ & 60 \\
\hline 11 & $\mathrm{~F}$ & 26 & 8 & 2 & 12 & 38 & 9 & 0.4 & 2 & 1 & $\begin{array}{l}\text { DGS, IgA, } \\
\text { MCD }\end{array}$ & $\begin{array}{l}\text { DM, IgA, } \\
\text { MCD }\end{array}$ & 43 \\
\hline 12 & $\mathrm{M}$ & 32 & 10 & 1 & 11 & 39 & 8 & 0.8 & 2 & 1 & $\begin{array}{l}\text { DGS, IgA, } \\
\text { MCD }\end{array}$ & $\begin{array}{l}\text { DM, IgA, } \\
\text { MCD }\end{array}$ & 26 \\
\hline 13 & $\mathrm{~F}$ & 23 & 4 & 2 & 18 & 39 & 6 & 0.1 & 3 & 2 & $\begin{array}{l}\text { Lupus } \\
\text { nephritis }\end{array}$ & $\begin{array}{l}\text { Lupus } \\
\text { nephritis }\end{array}$ & 38 \\
\hline 14 & $\mathrm{M}$ & 42 & 6 & 6 & 26 & 29 & 5 & 2 & 3 & 3 & Amyloidosis & $\begin{array}{l}\text { Amyloidosis } \\
\text { due to FMF }\end{array}$ & 32 \\
\hline 15 & $\mathrm{M}$ & 50 & 8 & 6 & 23 & 35 & 4 & 1 & 4 & 3 & $\begin{array}{l}\text { Light chain } \\
\text { disease }\end{array}$ & $\begin{array}{l}\text { Light chain } \\
\text { disease }\end{array}$ & 24 \\
\hline
\end{tabular}

Abbreviations: NS: nephrotic syndrome, M: male, F: female, DGS: diabetic glomerulosclerosis, MCD: minimal change disease, MG: membranous glomerulopathy, FSGS: focal and segmental glomerulosclerosis, IgA: immunoglobulin deposition disease.

\section{Case series:}

Cases (n: 1-3) presented with new-onset and severe NS within a month-period. Kidney biopsy had shown variable degree of mesangial expansion and occasional nodular glomerulosclerosis. Immunofluorescet stains showed occasional scanty membranous $\mathrm{IgG}$ deposits. Since they had acute and severe NS mismatching diabetic glomerulosclerosis (DGS); decision was made to treat as superimposed minimal change disease (MCD). They all improved within days and subsequently had received Rituximab (R) infusions (I $\mathrm{g}$ followed by another $1 \mathrm{~g} 2$ weeks later). The latter was adopted to avoid steroid-induced hyperglycemia and to ease management of their disease.

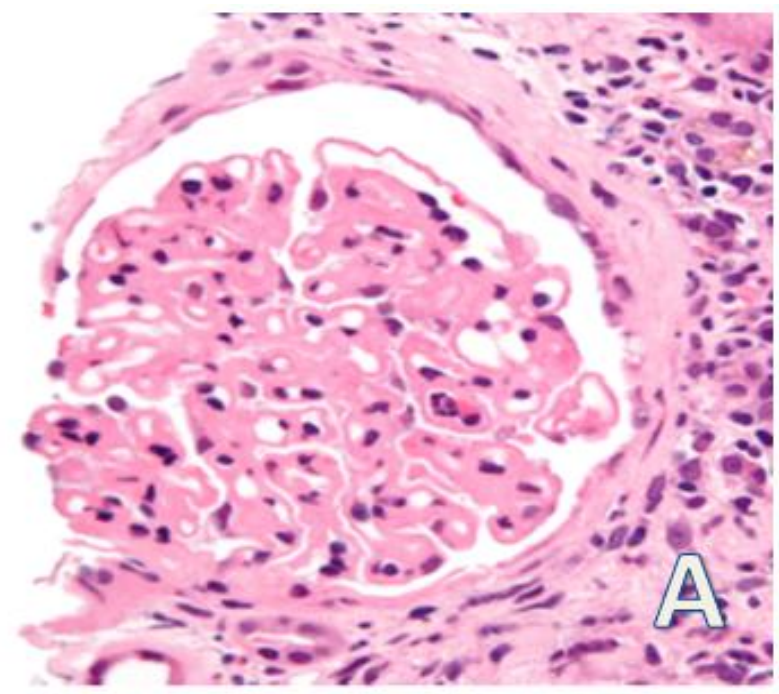

Cases $(n: 4,5)$ had similar presentation to the first 3 cases yet had mild yet progressive oedema over few months. Their kidney biopsy showed variable degree of mesangial expansion and occasional nodular glomerulosclerosis in addition to thickened capillary basement membrane with spikes on Silver stains and $3(+)$ granular membranous deposits of IgG (Fig.1). They were diagnosed as idiopathic membranous glomerulopathy (MG). They received Tacrolimus (T) and Mycophenolate mofetil (MMF) and had significant improvement within 2-3 weeks. They also had received $\mathrm{R}$ and 2 months later $\mathrm{T} \& \mathrm{MMF}$ were discontinued. On follow up they were stable on yearly $\mathrm{R}$ infusions.

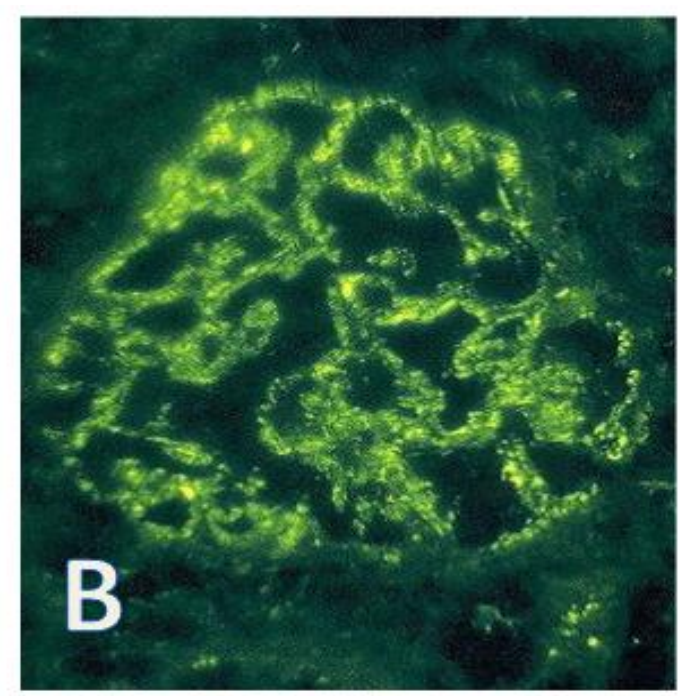

Fig 1: Photomicrograph of a kidney biopsy in patient (n: 4) showing diffuse thickening of glomerular basement membrane (A) and granular membranous deposition of IgG on immunofluorescence (B) (H\&E X 400). 
Case 6 presented with 3 month-history of progressive NS. He had new-onset hypertension and microscopic hematuria. Kidney biopsy had shown mild diabetic changes yet focal and segmental glomerulosclerosis (FSGS) with 3(+) deposits of IgM in the sclerosed areas. Her NS improved after treatment with T, MMF and later on yearly $\mathrm{R}$.

$\underline{\text { Case } 7}$ was a diabetic woman with mild proteinuria for years and had presented with progressive anasarca and renal failure that had required maintenance hemodialysis within 2 months. Kidney biopsy showed mild diabetic changes yet evident collapsing FSGS (Fig 2).

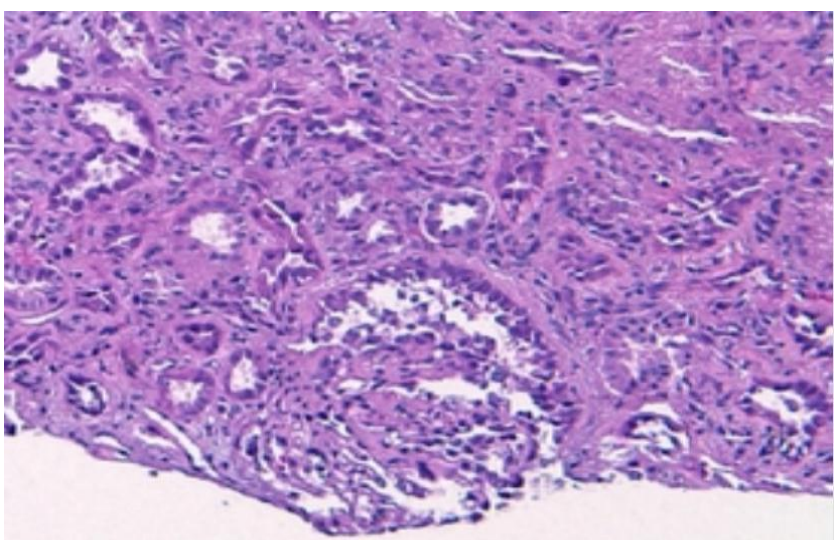

Fig 2: Photomicrograph of a kidney biopsy in patient (n: 7) showing collapsed glomerular capillary loops with obliteration of its vascular spaces, podocyte hyperplasia simulating pseudocrescent formation and interstitial nephritis (H\&E 200).

Case (n: 8) was a primgravidous woman who presented with severe NS and signs of pre-eclampsia (PE). The latter manifested as hypertension and progressive weight gain with progressive increase in uric acid and azotemia in her last trimester. Pregnancy was induced and she was treated with human albumin infusions with Lasix to control her anasarca. Since, her NS persisted; she was subjected to kidney biopsy. The latter showed mild endotheliosis yet evident FSGS with 3(+) deposits of IgM in the sclerosed areas. Initially, she was started on Prednisone $1 \mathrm{mg} / \mathrm{kg}$ for a possibility of MCD and her NS cleared within days. After delivery, Prednisone was replaced with $\mathrm{T}$ and MMF and had received R. Subsequently; $\mathrm{T}$ and MMF were discontinued within 1 month. One year later; her NS relapsed and was started on yearly R as a maintenance therapy. Subsequent pregnancy 3 months later proceeded normally.
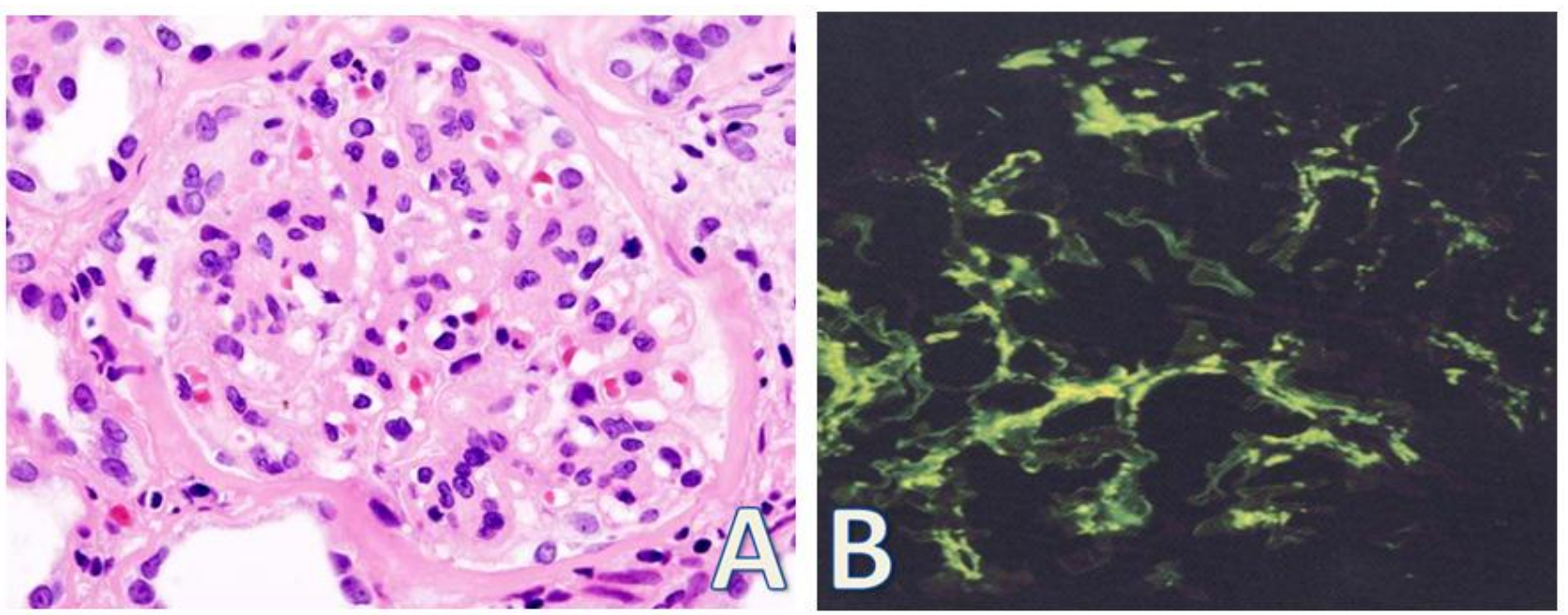

Fig 4: Photomicrographs of a kidney biopsy in patient (n: 11) showing focal proliferation of a glomerulus with mild mesangial expansion $(H \& E X ~ 400)$ in (A) and mesangial deposition of IgA on immunofluorescence in (B).

Case (n: 9) had developed sudden and severe NS in the last trimester of her pregnancy similar to the previous case except for being multiparous with 4 previous children. Her kidney biopsy showed changes similar to the previous case. Her management was similar to the previous case.

Case (n: 10) was similar to the previous 2 cases in the course of disease and management yet her kidney biopsy showed lobular pattern of her glomeruli with narrow capillary lumina due to marked mesangial and endothelial cell swelling (enotheliosis) (Fig. 3) consistent with PE. Since her NS was mismatching with PE; it was attributed to superimposed MCD on top of PE. Her management was similar to case $(8,9)$ since her NS relapsed 1 year later.

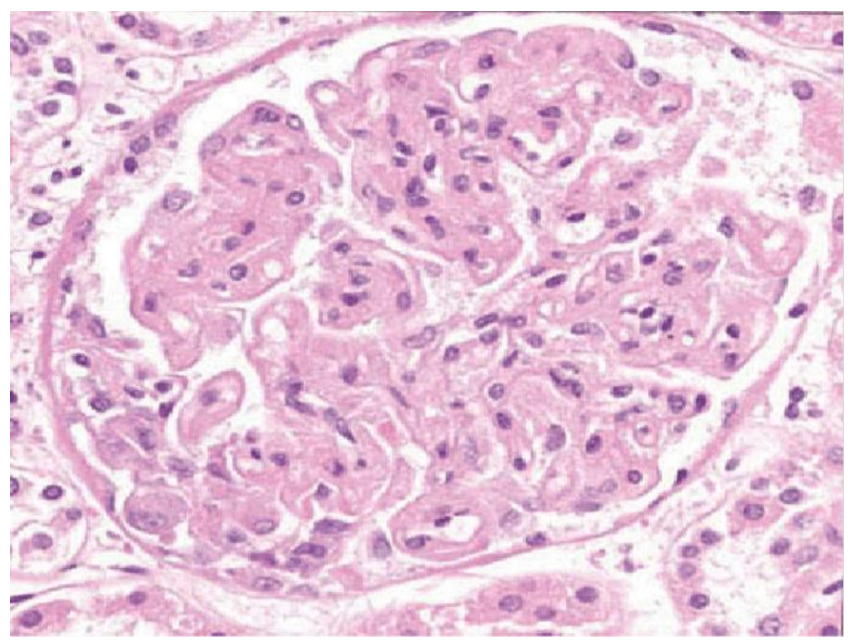

Fig 3: Photomicrograph of kidney biopsy in patient (n: 10) showing lobular pattern of a glomerulus with narrow capillary lumina due to marked mesangial and endothelial cell swelling (enotheliosis) (H\&E X 400).

Cases (n: 11 \& 12) had developed severe and sudden NS. Kidney biopsy showed mild mesangial expansion as well as focal proliferative glomerulonephritis with IgA deposits (Fig 4). Since those 2 diagnoses did not match their acute and severe NS; those 2 patients were treated empirically with Prednisone $1 \mathrm{mg} / \mathrm{kg} / \mathrm{day}$. Their NS cleared within 1 week indication a superimposed MCD on top of mild DGS \& immunoglobulin A deposition nephropathy $(\operatorname{Ig} \mathrm{A})$. 
Case (n: 13) presented with progressive NS and renal impairment. She did not have evidence of systemic manifestations of autoimmune disease and her peripheral leucocytic and platelets counts were normal. Hemoglobin was low at $100 \mathrm{~g} / \mathrm{L}$ with normal transferrin saturation\% and vitamin B12 level. Her urine routine showed microscopic hematuria. Serum complements (C3 \& C4), ANA and anti-dsDNA were normal. Kidney biopsy showed diffuse proliferative glomerulonephritis with deposition of $\mathrm{C} 3$ and all immunoglobulins (Fig 5). Final diagnosis of stage 4 lupus nephritis was established. She responded to Solumedrol $1 \mathrm{~g}$ IV daily for 3 days followed by Prednisone $1 \mathrm{mg} / \mathrm{kg} /$ day with MMF. After such induction therapy, she was stable with yearly $\mathrm{R}$ infusions.

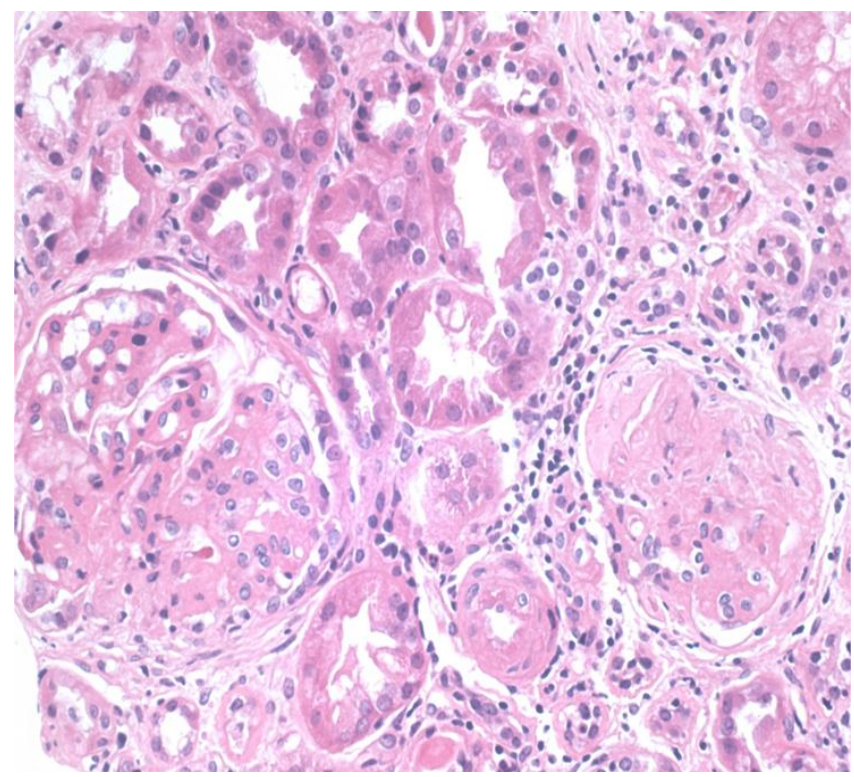

Fig 5: Photomicrograph of a kidney biopsy in patient (n: 14) showing diffuse proliferative glomerulonephritis with severe interstitial nephritis (H\&E X 200).

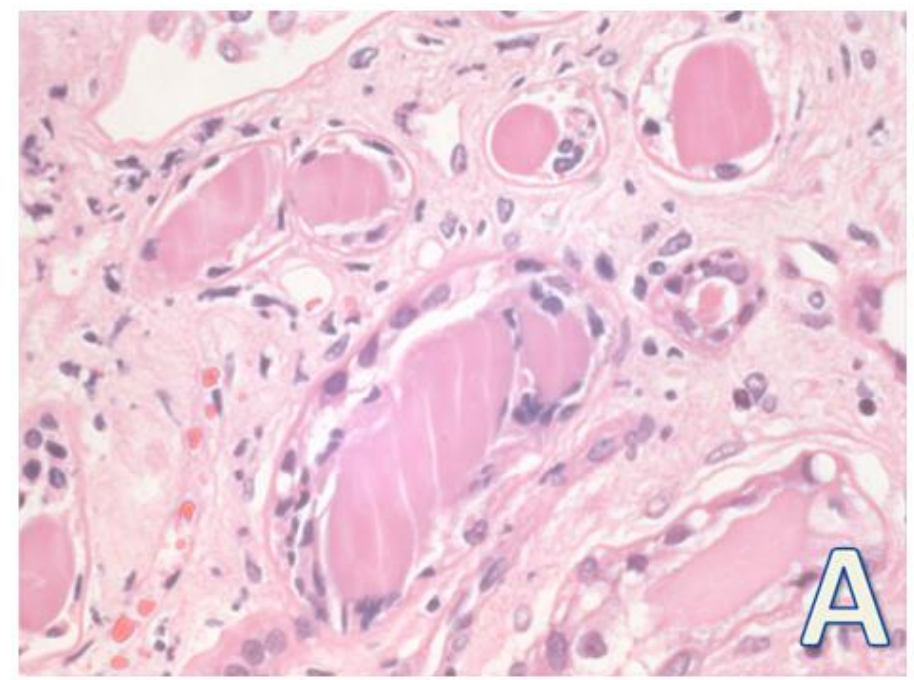

Cases (n: $14 \& 15$ ) had developed progressive and severe NS and progressive renal failure after short-duration of DM. Moreover, their hyperglycemia and hypertension were well controlled. Kidney biopsy, in both patients, revealed nodular glomerulosclerosis and Congo red stains were positive indicating diagnosis of amyloidosis (Fig 6). Patient (n: 14) did not have evidence of primary or secondary causes of amyloidosis. He was an Egyptian man with history of recurrent undisclosed abdominal pains. He was labeled clinically as Familial Mediterranean Fever (FMF) and was treated with Colchicine $0.5 \mathrm{mg}$ daily. His abdominal pains abated and his NS was more manageable. In addition to amyloidosis, the tubules in patient (n: 15) had multiple broad casts surrounded by cell infiltrate and on immunoperoxidase which stained exclusively for Kappa indicating multiple myeloma with light chain disease (Fig 7). He responded to Prednisone \& Melphalan therapy.

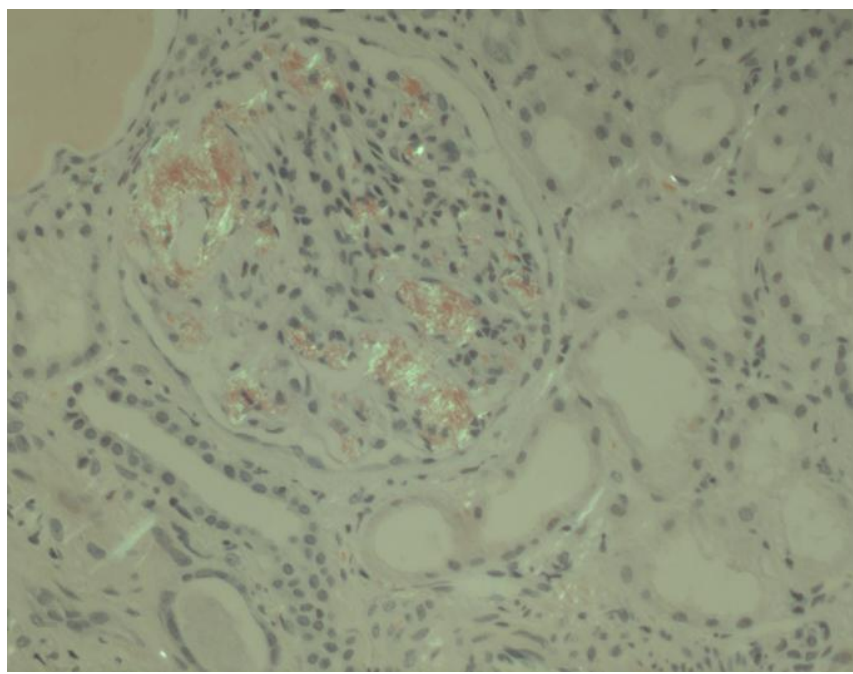

Fig 6: Photomicrograph of a kidney biopsy in patient (n: 15) showing nodular glomerular mesangial expansion with $(+)$ Congo red stain (Congo red X400).

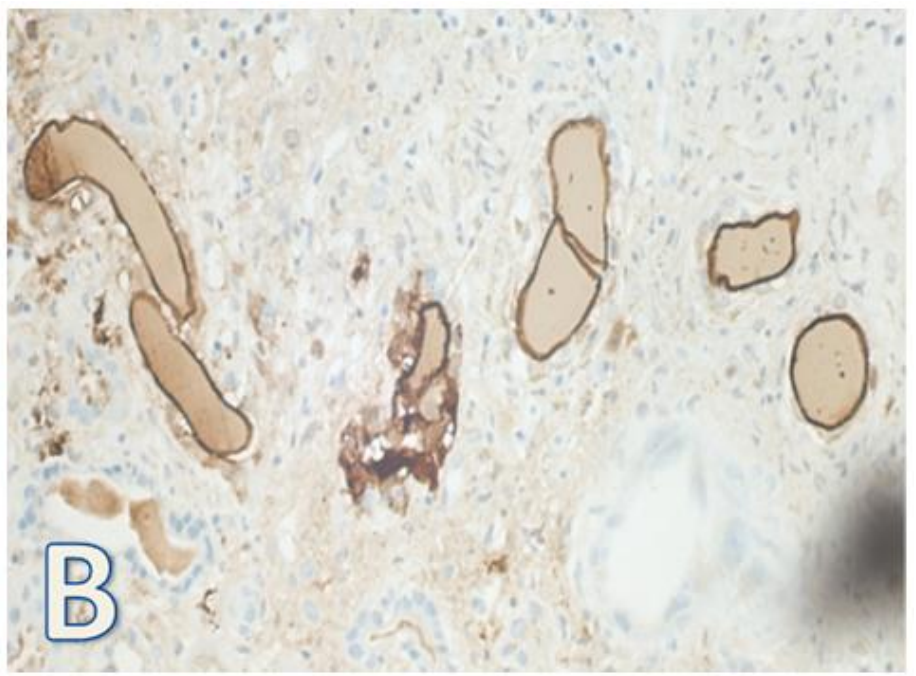

Fig 7: Photomicrograph of kidney biopsy of patient (n: 14) showing casts in tubules surrounded by inflammatory cell infiltrate and early fibrosis (H\&E X200) in (A) and positive immunoperoxidase stain for Kappa in (B).

\section{Discussion}

Clinicopathological correlation is an essential step in management of diabetic patients with renal disease. DKD includes 2 lesions. The first is DGS which is a slowly progressive albuminic disease affecting glomeruli with mesangial expansion followed by nodular lesions (Kimmelstiel-Wilson disease) till global sclerosis and ESRD $^{[8]}$. It is the most common type of DKD with prevalence at
$75 \%$ in biopsy reports. The second lesion is a non-albuminic phenotype which is characterized by tubulointerstitial and vascular disease. It has a relatively benign course compared with albuminuric DKD, with lower rates of dialysis and mortality ${ }^{[9]}$. The prevalence and type of NDKD in patients with DM reported in the literature is highly variable. This disparity reflects different selection criteria and study design, reporting bias, threshold for biopsy, and geographical as well as ethnic differences ${ }^{[10]}$. In the 
latter study, Mazzucco G, et al showed that despite patient's recruitment from an ethnically homogenous population belonging to the same geographic area, centers with unrestricted biopsy policies reported DGS in only $50 \%$ of those patients whereas centers with restricted biopsy policies had the majority of NDKD. The lesions described were either independent of, or superimposed on, DN. Glomerular causes of NDKD include IgA nephropathy, MG, membrano-proliferative glomerulonephritis, acute interstitial nephritis, hypertensive renal disease, FSGS and crescentic glomerulonephritis due to ANCA-associated disease and antiglomerular basement membrane glomerulonephritis.

Moreover, even in the presence of diabetic retinopathy, prediction of DKD based on clinical course of disease and laboratory findings had only $65 \%$ sensitivity and $76 \%$ specificity ${ }^{[11]}$. In our center we have unrestricted biopsy policy. In our study, mismatched clinicopathological feature of NS indicated biopsy of diabetic patients and those with PE. The first 3 patients had longstanding DM and their kidney biopsy showed variable features of DKD yet a 1-month history of severe NS is not typical of DGS. To disclose a superimposed MCD a short course of empiric therapy with Prednisone was tried. Such therapeutic trial, in this diabetic patient, is not without risk of severe hyperglycemia and electrolytes disturbance. After confirming diagnosis; Prednisone was replaced with T \& MMF 2 weeks later to avoid long-term Corticosteroid side effects. As a maintenance therapy, $\mathrm{R}$ was ideal in this patient population and its use limited disease recurrence ${ }^{[12]}$. In the next 2 patients kidney biopsy was done, despite a misleading gradual NS, since they had short duration of DM. T \& MMF were used at start since MG is Corticosteroid-resistant and to avoid its associated hyperglycemia ${ }^{[13]}$. Subsequently; yearly $\mathrm{R}$ was their maintenance therapy to avoid relapses in the next 4-5 years. Patient (n: 6) had a typical presentation of DGS with 3-month history of NS associated with hypertension and hematuria with short duration of DM. His renal biopsy revealed idiopathic FSGS and he responded to treatment with T, M and later on yearly $\mathrm{R}$. The next patient; developed persistent oliguric renal failure and hence indicated kidney biopsy. The latter showed disclosed a non-HIV collapsing FSGS which has an ominous renal prognosis ${ }^{[14]}$. The next group of patients had developed sudden and severe NS in the last trimester of pregnancy. Though their kidney biopsy has shown variable features of PE yet FSGS was evident in the first 2 patients and hence had received immunosuppressive treatment. Despite a kidney biopsy showing only PE changes; the third pregnant patient; was treated as MCD since her presentation was not typical of PE and had responded to empiric therapy ${ }^{[15]}$. The subsequent group included 2 patients with biopsy proven DGS and also IgA. Since their sudden and severe NS was a typical for their short duration of DM and IgA disease; MCD was suspected ${ }^{[5,16]}$. Again the empiric Prednisone course confirmed the diagnosis. In patient (n: 13) kidney biopsy was done since she had (a) progressive severe NS and renal failure which are atypical of DGS, (b) negative serology for systemic diseases. Her biopsy disclosed stage 4 lupus nephritis and fortunately, she responded to our modified immunosuppressive therapy ${ }^{[17]}$. In the last 2 patients; their clinical features were suggestive of DGS yet persistent microscopic hematuria and progressive NS with renal impairment indicated their kidney biopsy. Their latter disclosed amyloidosis attributable to light chain disease and FMF ${ }^{[18,19]}$. Subsequent treatment improved their NS and hence their prognosis. In conclusion; renal biopsy should be considered in diabetics with atypical presentation of NS and clinicopathological correlation is essential to assess for superimposed NDKD.

\section{References}

[1] International Diabetes Federation. IDF Diabetes Atlas, 9th edn. Brussels, Belgium: 2019.

[2] World Health Organization, Global Report on Diabetes. Geneva, 2016.

[3] National Kidney Foundation. KDOQI Clinical Practice Guideline for Diabetes and CKD: 2012 Update. Am J Kidney Dis 2012; 60: 850-886.

[4] Mazzucco G, Bertani T, Fortunato M, et al. Different patterns of renal damage in type 2 diabetes mellitus: A multicentric study on 393 biopsies. Am J Kidney Dis 2002; 39: 713-720.

[5] NKF, Shimizu M, Furuichi K, Toyama T, et al. Longterm outcomes of Japanese type 2 diabetic patients with biopsy-proven diabetic nephropathy. Diabetes Care 2013; 36: 3655-3662.

[6] Umanath K, Lewis HB. Update on diabetic glomerulosclerosis: core curriculum 2018. AJKD 2018; 71: 884-895.

[7] Mak SK, Gwi E, Chan KW, et al. Clinical predictors of non-diabetic renal disease in patients with non-insulin dependent diabetes mellitus. Nephrol Dial Transplant 1997; 12: 2588-2591.

[8] Tervaert TW, Mooyaart AL, Amann K, et al. Pathologic classification of diabetic nephropathy. J Am Soc Nephrol 2010; 21: 556-563.

[9] Hoefield RA, Kalra PA, Baker PG, et al. The use of eGFR and ACR to predict decline in renal function in people with diabetes. Nephrol Dial Transplant 2011; 26: 887-892.

[10] Mazzucco G, Bertani T, Fortunato $M$ et al. Different patterns of renal damage in type 2 diabetes mellitus: A multicentric study on 393 biopsies. Am J Kidney Dis 2002; 39: 713-720.

[11] Bergner R, Lenz T, Henrich DM, Hoffmann M, Uppenkamp M. Proteinuria in diabetic patients - is it always diabetic nephropathy? Kidney Blood Press Res 2006; 29: 48-53.

[12] Kamel El-Reshaid, Hossam Eldin Tawfik Salla, Abass Ali Hakim, Raja Al-Atiyaa. Rituximab in treatment of idiopathic glomerulopathy. Saudi Journal of kidney diseases and transplantation 2012; 23: 973-978.

[13] Bomback AS, Fervenza FC. Membranous nephropathy: approaches to treatment. Am J Nephrol 2018; 47 (suppl 1): $30-42$.

[14] Albaqumi M, Soos TJ, Barisoni L, Nelson PJ. Collapsing glomerulopathy. JASN 2006; 17: 2854-2863.

[15] Sperling, Jeffrey D.; Gossett, Dana R. Screening for Preeclampsia and the USPSTF Recommendations. JAMA 2017; 317: 1629-1630.

[16] Wyatt RJ, Julian BA. IgA nephropathy. N Engl J Med 2013; 368: 2402-14.

[17] El-Reshaid W, El-Reshaid K, Kapoor M, Madda JP. Glomerulopathy in Kuwait : The spectrum over the past 7 years. Renal Failure 2003; 25: 619-630.

[18] Kanzaki G, Okabayashi Y, Nagahama K, Ohashi R, Tsuboi N, Yokoo T, et al. Monoclonal Immunoglobulin Deposition Disease and Related Diseases. J Nippon Med Sch 2019; 86:2-9.

[19] Dember LM. Amyloidosis-associated kidney disease. J Am Soc Nephrol 2006; 17: 3458-2471. 